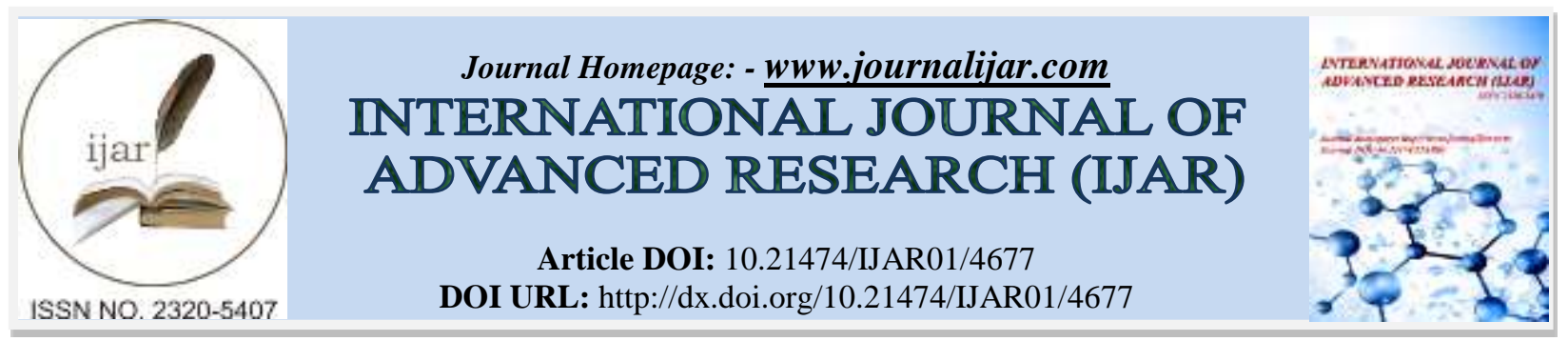

RESEARCH ARTICLE

\title{
EFFICIENT SOLUTION OF A MULTI-OBJECTIVE BULK TRANSPORTATION PROBLEM.
}

\author{
Sungeeta Singh ${ }^{1}$, Sudhir Kumar Chauhan ${ }^{2}$ and Kuldeep ${ }^{2}$. \\ 1. Department of Mathematics, Amity University, Gurugram, Haryana, India. \\ 2. Department of Mathematics, Amity School of Engineering and Technology, Bijwasan, New Delhi, India.
}

\section{Manuscript Info}

Manuscript History

Received: 27 April 2017

Final Accepted: 29 May 2017

Published: June 2017

Key words:-

Multi-Objective, Pareto-Optimal, Cost-

Time Trade-Off, Bulk Transportation.

\section{Abstract}

In the present work, a simple method to obtain the efficient cost-time trade-off pairs in Multi-Objective Bulk Transportation Problem (MOBTP) is proposed. This work provides a very simple alternate procedure to determine all efficient cost-time trade-off pairs. The motivation of this work came from different efficient solution pairs obtained by the methods of existing researchers [6,12,14].The proposed method unifies the existing methods to get all exhaustive solution pairs. A comparative study among the existing methods and the proposed method is also shown.

Copy Right, IJAR, 2017,. All rights reserved.

\section{Introduction:-}

The Classical Transportation Problem(CTP) is a single objective transportation problem. It has applications in network flow optimization where it is required to determine the minimum cost transportation schedule. The CTP was first studied by Hitchcock [7]. Later on, Koopmans [8] and Dantzig [4] and several other authors studied the single objective transportation problem.

However, in real life situations, transportation problems can be formulated as Multi-Objective Transportation Problems(MOTP). In MOTP, objectives may be of minimizing the total time of transportation, total cost of transportation and total deterioration of products during transportation etc. Pareto Optimal solutions of the MOTP with two objectives viz. minimizing the total cost and the total time of transportation have been studied by Bhatia et al. [3]. Later on, similar MOTP was studied by Theodore and Berger [18]. Aneja and Nair [1] presented a method based on parametric approach for determining all the non-dominated extreme points of the MOTP. Prakash et al. [7] solved the MOTP while keeping the time of transportation as fixed. Later on, Purusotham et al. [15] proposed a method for solving the MOTP.

Bulk Transportation Problem(BTP) is a particular case of the classical transportation problem in which demand of each destination must be fulfilled from only one source. Maio and Roveda [9] were the first who developed the BTP with the objective of minimizing the total cost of bulk transportation. Srinivasan and Thompson [17] studied the BTP of Maio and Roveda [9] with help of branch and bound method. Later on, Murthy [10] proposed a method based on lexicographic minimum to solve the BTP. The time minimizing BTP is studied by Bhatia [3] and Foulds and Gibbons [5]. A MOBTP is solved by Prakash and Ram [13] using branch and bound method. Prakash et al. [14, 15] obtained the Pareto Optimal solutions of MOBTP using branch and bound method in the formal and Extremum Difference Method in the latter. 
In this work, method by Quddoos et al. [16] is extended to study the cost-time trade-off relationship in MOBTP. In the present paper, Section 2 presents the formulation of MOBTP and Section 3 describes the steps of the proposed method. In Section 4, the proposed method is applied on a numerical example of Gupta et al. [6] and lastly, Section 5 gives the comparative study of existing methods and proposed method for solving a MOBTP along with discussion.

\section{Formulation of the Problem:-}

Let there be $\mathrm{m}$ sources each producing $a_{i}(i=1,2,3, \ldots \ldots, m)$ number of units of a certain product and $\mathrm{n}$ destinations each having requirement of $b_{j}(j=1,2,3, \ldots \ldots, n)$ units. Let $\mathrm{C}$ and $\mathrm{T}$ denote the total cost and total time of transportation respectively.

The mathematical formulation of the MOBTP is as follows:

Minimize

$C=\sum_{i=1}^{m} \sum_{j=1}^{n} c_{i j} x_{i j}$

$T=\max \left\{t_{i j}: x_{i j}=1 ;=1,2, \ldots, m ; j=1,2, \ldots, n\right\}$

subject to the constraints

$\sum_{j=1}^{n} b_{j} x_{i j} \leq a_{i}(i=1,2, \ldots, m)$

$\sum_{i=1}^{m} x_{i j}=1(j=1,2, \ldots, n)$

$x_{i j}=1$ or $0(i=1,2, \ldots ., m ; j=1,2, \ldots n)$

where $a_{i}$ is the number of units of a product available at the $i$ th source.

$b_{j}$ is the number of units of a product required at $j$ th destination.

$c_{i j}$ denotes the bulk cost of transportation of $b_{j}$ units of the product from ith source to $j$ th destination.

$t_{i j}$ is the bulk time of transportation of $b_{j}$ units of the product from ith source to $j$ th destination.

$x_{i j}$ is the decision variable assuming value 1 or 0 depending upon whether the source $i$ fulfills the demand of the destination $j$ or not.

Definition(ith efficient solution/cost- time pair): Let $C_{1}$ be the minimum cost of bulk transportation and $T_{1}$ be the corresponding time of bulk transportation. Let $Z_{1}$ be the solution for the first efficient cost-time pair $\left(C_{1}, T_{1}\right)$. Let $C_{2}\left(>\mathrm{C}_{1}\right)$ be another cost of bulk transportation and $T_{2}\left(<T_{1}\right)$ be the minimum time of bulk transportation at cost $C_{2}$. Then the solution $Z_{2}$ for the second efficient cost-time trade off pair $\left(C_{2}, T_{2}\right)$ is said to be a second efficient solution if there exists no other solution pair $(C, T)$ s.t. $C_{1}<C<C_{2}$ and $T_{2}<T<T_{1}$. In a similar manner as above,the ith efficient (i>2)solution/cost-time tradeoff pairs may be obtained.

\section{Algorithm:-}

There are two main steps in the proposed algorithm. In step 1, the first efficient cost-time tradeoff pair is obtained while in step 2, the subsequent efficient trade-off pairs are obtained. The detailed steps are as follows:

Step1.

1. Delete the cells $(i, j)$ from the initial multi-objective transportation table for which requirement of destination $b_{j}(j=1,2, \ldots, n)$ exceeds the availability of source $a_{i}(i=1,2, \ldots \ldots, m)$.

2. Select the least bulk cost for each row and deduct it from all the bulk costs of corresponding row. Apply the same process for each column also.

3. For each zero in the reduced cost matrix, count the number of zeros in corresponding row and column except itself.

4. Allocate 1 to the cell in the reduced cost matrix for which number of zeros is least. If there is tie, then select the zero for which sum of all the entries in the corresponding row and column is largest. Again, if there is tie in sum, then select the cell for which maximum allocation can be made.

5. Remove the destination from the table whose demand is satisfied and also remove the source whose availability becomes 0 or less than demand of each destination. Repeat the steps (i) to (v) until all the destinations met their demands.

Step 2:-

To determine the next efficient cost-time trade-off pair, define the new cost matrix of MOBTP as shown below:

$$
c^{1}{ }_{i j}=\left\{\begin{array}{l}
\infty ; t_{i j} \geq T_{1} \\
c_{i j} ; t_{i j}<T_{1}
\end{array}\right.
$$


Repeat step 1 to obtain the subsequent cost-time trade-off pair of MOBTP. In this way, on the repetition of steps 1 and 2, we obtain all the cost-time trade-off pairs of MOBTP.

\section{Numerical Example:-}

The problem studied by Gupta et al. [6] is considered here in which there are three sources $S_{1}, S_{2}, S_{3}$ with availabilities 7, 8, 9 units respectively and five destinations $D_{1}, D_{2}, D_{3}, D_{4}, D_{5}$ with requirements $3,5,4,6,2$ units respectively. In table 1 , the first and second entry in each cell denotes the bulk cost $c_{i j}$ of transportation and bulk time $t_{i j}$ of transportation respectively. The proposed method is applied on the considered problem to determine the cost-time trade-off pairs.

Table 1;- (Initial Cost and Time Representation of MOBTP)

\begin{tabular}{|c|c|c|c|c|c|c|}
\hline & $\mathrm{D}_{1}$ & $\mathrm{D}_{2}$ & $\mathrm{D}_{3}$ & $\mathrm{D}_{4}$ & $\mathrm{D}_{5}$ & $a_{i} \downarrow$ \\
\hline $\mathrm{S}_{1}$ & $(10,5)$ & $(9,6)$ & $(11,3)$ & $(7,2)$ & $(8,3)$ & 7 \\
\hline $\mathrm{S}_{2}$ & $(11,2)$ & $(10,3)$ & $(13,5)$ & $(14,6)$ & $(12,4)$ & 8 \\
\hline $\mathrm{S}_{3}$ & $(8,4)$ & $(6,5)$ & $(9,8)$ & $(10,3)$ & $(13,8)$ & 9 \\
\hline$b_{j} \rightarrow$ & 3 & 5 & 4 & 6 & 2 & \\
\hline
\end{tabular}

Since availability of each source exceeds the requirement of each destination, no cell is deleted from the Table 1. Apply steps (i) and (ii) on the corresponding cost matrix of MOBTP, the reduced cost matrix is shown in Table 2.

Table 2:- (Reduced table after first two sub-steps of step 1).

\begin{tabular}{|c|c|c|c|c|c|c|}
\hline & $\mathrm{D}_{1}$ & $\mathrm{D}_{2}$ & $\mathrm{D}_{3}$ & $\mathrm{D}_{4}$ & $\mathrm{D}_{5}$ & $a_{i} \downarrow$ \\
\hline $\mathrm{S}_{1}$ & 2 & 2 & 1 & 0 & 0 & 7 \\
\hline $\mathrm{S}_{2}$ & 0 & 0 & 0 & 4 & 1 & 8 \\
\hline $\mathrm{S}_{3}$ & 1 & 0 & 0 & 4 & 6 & 9 \\
\hline$b_{j} \rightarrow$ & 3 & 5 & 4 & 6 & 2 & \\
\hline
\end{tabular}

Applying the steps (iii) to (v), we have $x_{14}=1$ and the reduced cost matrix table 3 is shown in Table 3 .

Table 3:- (Reduced table after $1^{\text {st }}$ application of step 1)

\begin{tabular}{|c|c|c|c|c|c|}
\hline & $\mathrm{D}_{1}$ & $\mathrm{D}_{2}$ & $\mathrm{D}_{3}$ & $\mathrm{D}_{5}$ & $a_{i} \downarrow$ \\
\hline $\mathrm{S}_{2}$ & 0 & 0 & 0 & 1 & 8 \\
\hline $\mathrm{S}_{3}$ & 1 & 0 & 0 & 6 & 9 \\
\hline$b_{j} \rightarrow$ & 3 & 5 & 4 & 2 & \\
\hline
\end{tabular}

Again, applying step 1, we have $x_{32}=1$ and the reduced cost matrix is shown in Table 4 .

Table 4:- (Reduced table after $2^{\text {nd }}$ application of step 1)

\begin{tabular}{|c|c|c|c|c|}
\hline & $\mathrm{D}_{1}$ & $\mathrm{D}_{3}$ & $\mathrm{D}_{5}$ & $a_{i} \downarrow$ \\
\hline $\mathrm{S}_{2}$ & 0 & 0 & 0 & 8 \\
\hline $\mathrm{S}_{3} \rightarrow$ & 1 & 0 & 5 & 4 \\
\hline$b_{j}$ & 3 & 4 & 2 & \\
\hline
\end{tabular}

Again, applying step 1, we have $x_{33}=1$ and the reduced cost matrix is shown in Table 5 .

Table 5:- (Reduced table after $3^{\text {rd }}$ application of step 1)

\begin{tabular}{|c|c|c|c|}
\hline & $\mathrm{D}_{1}$ & $\mathrm{D}_{5}$ & $a_{i} \downarrow$ \\
\hline $\mathrm{S}_{2}$ & 0 & 0 & 8 \\
\hline$b_{j} \rightarrow$ & 3 & 2 & \\
\hline
\end{tabular}

Again, applying step 1, we have $x_{21}=1$ and the reduced cost matrix is shown in Table 6

Table 6:- (Reduced table after $4^{\text {th }}$ application of step 1)

\begin{tabular}{|c|c|c|}
\hline & $\mathrm{D}_{5}$ & $a_{i} \downarrow$ \\
\hline $\mathrm{S}_{2}$ & 0 & 5 \\
\hline$b_{j} \rightarrow$ & 2 & \\
\hline
\end{tabular}


Finally, we have $x_{25}=1$. Thus, requirements of all destinations are satisfied and the solution of the problem is given by $X_{1}=\left\{x_{21}, x_{32}, x_{33}, x_{14}, x_{25}\right\}$. Therefore, cost of bulk transportation is $C_{1}=C\left(X_{1}\right)=45$ and corresponding time of bulk transportation is $T_{1}=T\left(X_{1}\right)=8$. Thus, the first cost-time trade-off pair is $\left(C_{1}, T_{1}\right)=(45,8)$.

To obtain the $2^{\text {nd }}$ cost-time trade-off pair, the given BTP is reduced using step 2 and table 7 is obtained as shown below.

Table 7:- (Reduced MOBTP after step 2).

\begin{tabular}{|c|c|c|c|c|c|c|}
\hline & $\mathrm{D}_{1}$ & $\mathrm{D}_{2}$ & $\mathrm{D}_{3}$ & $\mathrm{D}_{4}$ & $\mathrm{D}_{5}$ & $a_{i} \downarrow$ \\
\hline $\mathrm{S}_{1}$ & $(10,5)$ & $(9,6)$ & $(11,3)$ & $(7,2)$ & $(8,3)$ & 7 \\
\hline $\mathrm{S}_{2}$ & $(11,2)$ & $(10,3)$ & $(13,5)$ & $(14,6)$ & $(12,4)$ & 8 \\
\hline $\mathrm{S}_{3}$ & $(8,4)$ & $(6,5)$ & $(9, \infty)$ & $(10,3)$ & $(13, \infty)$ & 9 \\
\hline$b_{j} \rightarrow$ & 3 & 5 & 4 & 6 & 2 & \\
\hline
\end{tabular}

Following the proposed algorithm for the reduced MOBTP, the second efficient solution obtained is $X_{2}=$ $\left\{x_{31}, x_{32}, x_{23}, x_{14}, x_{25}\right\}$.The second efficient cost-time trade-off pair is $\left(C_{2}, T_{2}\right)=(46,5)$. Similarly, the third and fourth efficient solutions are $X_{3}=\left\{x_{31}, x_{22}, x_{13}, x_{34}, x_{15}\right\}$ and $X_{4}=\left\{x_{21}, x_{22}, x_{13}, x_{34}, x_{15}\right\}$ having cost-time trade off pairs as $\left(C_{3}, T_{3}\right)=(47,4)$ and $\left(C_{4}, T_{4}\right)=(50,3)$ respectively. Thus, the exhaustive cost-time trade-off pairs are $(45,8),(46,5),(47,4)$ and $(50,3)$.

\section{Comparative Study and Discussion:-}

A comparative study is done on the number of cost-time trade-off pairs provided by the existing methods[6,12,14] and the proposed method. It is seen that the proposed method provides more number of cost-time trade-off pairs as compared to existing method [6]. This increase in the number of cost-time pairs may be seen to lend a greater flexibility to the user; who can make decisions according to his requirement.

Also, it is seen that the proposed method provides same number of cost-time trade-off pairs as compared to existing methods [12, 14]. However, the proposed method is relatively much easier to apply vis-à-vis methods [12, 14]. Therefore, it can be concluded that the proposed method provides a simple and useful tool to determine the exhaustive cost-time trade-off pairs in MOBTP.The results of the comparative study are shown in Table 8.

Table 8:- (Comparative Study)

\begin{tabular}{|c|c|c|c|}
\hline Parameters & $\begin{array}{l}\text { Method of Gupta et } \\
\text { al. [6] }\end{array}$ & $\begin{array}{l}\text { Methods of Prakash et } \\
\text { al. }[12,14]\end{array}$ & Proposed Method \\
\hline $\begin{array}{l}1^{\text {st }} \text { solution Vector and associated cost- } \\
\text { time trade-off pair }\end{array}$ & $\begin{array}{l}X_{1}= \\
\left\{x_{21}, x_{32}, x_{33}, x_{14}, x_{25}\right\} \\
\quad(45,8)\end{array}$ & $\begin{array}{l}X_{1}= \\
\left\{x_{21}, x_{32}, x_{33}, x_{14}, x_{25}\right\} \\
\quad(45,8)\end{array}$ & $\begin{array}{l}X_{1}= \\
\left\{x_{21}, x_{32}, x_{33}, x_{14}, x_{2}\right. \\
\quad(45,8)\end{array}$ \\
\hline $\begin{array}{l}2^{\text {nd }} \text { solution Vector and associated cost- } \\
\text { time trade-off pair }\end{array}$ & $\begin{array}{l}X_{2}= \\
\left\{x_{31}, x_{22}, x_{13}, x_{34}, x_{15}\right\} \\
\\
(47,4)\end{array}$ & $\begin{array}{l}X_{2}= \\
\left\{x_{31}, x_{32}, x_{23}, x_{14}, x_{25}\right\}\end{array}$ & $\begin{array}{l}X_{2}= \\
\left\{x_{31}, x_{32}, x_{23}, x_{14}, x_{2}\right. \\
(46,5)\end{array}$ \\
\hline $\begin{array}{l}3^{\text {rd }} \text { solution Vector and associated cost- } \\
\text { time trade-off pair }\end{array}$ & $\begin{array}{l}X_{3} \\
=\left\{x_{21}, x_{22}, x_{13}, x_{34}, x_{1}\right. \\
\quad(50,3)\end{array}$ & $\begin{array}{l}X_{3} \\
=\left\{x_{31}, x_{22}, x_{13}, x_{34}, x_{15}\right\} \\
\quad(47,4)\end{array}$ & $\begin{array}{l}X_{3} \\
=\left\{x_{31}, x_{22}, x_{13}, x_{34}\right. \\
\quad(47,4)\end{array}$ \\
\hline $\begin{array}{l}4^{\text {th }} \text { solution Vector and associated cost } \\
\text { time trade-off pair }\end{array}$ & None & $\begin{array}{l}X_{4} \\
=\left\{x_{21}, x_{22}, x_{13}, x_{34}, x_{15}\right\} \\
\quad(50,3)\end{array}$ & $\begin{array}{l}X_{4} \\
=\left\{x_{21}, x_{22}, x_{13}, x_{34}\right. \\
\quad(50,3)\end{array}$ \\
\hline
\end{tabular}




\section{References:-}

1. Aneja, Y. P., Nair, K. P. K., "Bicriteria transportation problem, Management Science”, Vol. 25, No. 1, pp. 73-78(1979).

2. Bhatia, H.L, Puri, M.C. and Swarup, K., "Time-cost trade-off in a transportation problem", Opsearch, Vol. 13, pp. 129-142(1976).

3. Bhatia, H.L., "A note on a zero-one time minimizing transportation problem", NZOR, Vol.7, pp. 159165(1979).

4. Dantzig, G.B., "Linear Programming and Extensions", Princeton University Press, Princeton, New Jersey, 1963.

5. Foulds, L. R., and Gibbons, P. B., "New Algorithms For The Bulk, Zero-One Time Mini-Max Transportation Model",. NZOR Vol. 8, No. 2(1980).

6. Gupta, A., Verma, V., Puri, M. C., “ Time-Cost Trade-off Relations in Bulk transportation Problems”, Journal of Information \& Optimization Sciences. Vol. 16, No. 2, pp. 317-325(1995).

7. Hitchcock, F.L., "The distribution of a product from several sources to numerous locations", Journal of Mathematics and Physics Vol.20, pp. 224-230(1941).

8. Koopmans, T.C. "Optimum utilization of Transportation System", Econometrica, supplement Vol. 17(1949).

9. Maio, A.D., Roveda, C. "An all zero-one algorithm for a certain class of transportation problems", Operations Research, Vol. 19, pp. I406-1418 (1971).

10. Murthy, M.S., “ A bulk transportation problem”, Opsearch, Vol. 13, pp. I43-155(1976).

11. Prakash, S., Agarwal, A.K., Shah, S., "Non dominated solutions of cost-time trade-off transportation and assignment problems", Opsearch Vol. 25, pp. 126-131(1988).

12. Prakash, S., Kumar, P.,Prasad, B.V.N.S., Gupta, A., "Pareto optimal solutions of a cost -time trade-off bulk transportation problem", Eur.J. Oper. Res. Vol.188, pp. 85-110(2008).

13. Prakash, S., Ram, P.P., "A bulk transportation problem with objectives to minimize total cost and duration of transportation", The Mathematics Student. Vol.64, pp. 206-214 (1995).

14. Prakash, S.,Sharma, M.K., Singh, A. "An efficient heuristic for multi-objective bulk transportation problem", IEEE, pp. 1005-1009(2009).

15. Purusotham, S., Prakash, S., Dhyani, P., “ A transportation problem with minimization of duration and total cost of transportation as high and low priority objectives respectively",Bulletin of the Technical University of Istanbul, Vol. 37, pp. 1-11(1984).

16. Quddoos. A., Javaid. S., Khalid, M.M. "A new method for finding an optimal solution for transportation problem”, International Journal on Computer Science and Engineering, Vol. 4, pp.

17. 1271-1274(2012).

18. Srinivasan, V., Thompson, G.L., "An algorithm for assigning uses to sources in a special class of transportation problems", Operations Research, Vol. 21, pp. 284-295(1973).

19. Theodore, S. G., Berger, P. D., "Cost/Completion-date trade-off in the transportation problem", Operation Research, Vol. 25, No.1, pp. 163-168(1977). 